\title{
Admissions and mortality over a 5-year period in a limited-resource neonatal unit in Ghana
}

\author{
Adziri H. Sackey ${ }^{1}$ and Lily G Tagoe ${ }^{2}$
}

Ghana Med J 2019; 53(2): 117-125 doi: http://dx.doi.org/10.4314/gmj.v53i2.6

${ }^{1}$ Department of Child Health, School of Medicine and Dentistry, University of Ghana, Accra, Ghana ${ }^{2}$ Department of Child Health, Korle-Bu Teaching Hospital, Accra, Ghana.

\author{
Corresponding author: Adziri H. Sackey $\quad$ E-mail: $\underline{\text { sackey@sky.com }}$ \\ Conflict of interest: None Declared
}

\section{SUMMARY}

Objective: To review admissions and deaths at the neonatal intensive care unit (NICU) of the Korle Bu Teaching Hospital (KBTH), Ghana from 2011 to 2015, for the purposes of documentation of outcomes and identification of areas for improvement.

Design: A retrospective descriptive study of NICU Admissions \& Discharges from 2011 to 2015. All data in the NICU Admissions \& Discharge books were transferred into a spreadsheet and analysed.

Setting - The NICU of KBTH provides secondary and tertiary care for premature and critically ill term babies in the southern half of Ghana.

Results: Over the 5-year period, 9213 babies were admitted to the NICU. Admission weights ranged from 300 to $6700 \mathrm{~g}$ with median of $2400 \mathrm{~g}$. Overall mortality rate was $19.2 \%$. Mortality rates were progressively and significantly higher in babies with lower admission weights and earlier gestations.

Conclusions: We report a high NICU mortality rate of $19.2 \%$, compared to the worldwide range of $3.1 \%$ to $29 \%$. This wide range of outcomes is attributable to differences in the severity of illness of patients and to the organisation of resources devoted to obstetric and neonatal care. To substantially improve perinatal and neonatal outcomes, there is a need for wider coverage and better quality of health care; and to consider rationing of care. Complex interventions are necessary to improve outcomes, not just an increase in the allocation of particular resources.

Keywords: Intensive Care, Neonatal; developing countries; mortality rate Funding: None declared

\section{INTRODUCTION}

The measurement of institutional neonatal admissions and mortality is important for several reasons - to document workload and outcomes, to compare with past performance and with other institutions, to help identify potential areas for improvement, to show whether allocated resources are being effectively utilised, and to make a case for more resources.

The mortality rate in a neonatal unit reflects quality of care but is also profoundly affected by the severity of illness of neonates offered for admission. These two factors are in turn determined by national resource allocation to health and education, by the effectiveness of obstetric services, and by individual patient factors including congenital anomalies, maternal health, financial and educational status. ${ }^{1}$
The Neonatal Intensive Care Unit (NICU) of the Korle$\mathrm{Bu}$ Teaching Hospital (KBTH) in Ghana provides care for premature and critically ill term babies. It has a nominal capacity of 60 cots, warming platforms and incubators, though this number is often exceeded. The unit receives referrals from health facilities in the southern half of Ghana.

The aim of this study was to review the numbers of admissions and deaths at the NICU of the Korle Bu Teaching Hospital, from 2011 to 2015, for the purposes of documentation, analysis of associated factors, dissemination, and the provision of data to facilitate planning and improvement of neonatal outcomes. 


\section{METHODS}

All data in the NICU Admissions \& Discharge (A\&D) books from 2011 to 2015 were transferred into a spreadsheet (Microsoft Excel), checked carefully for transcription errors, and analysed with Microsoft Excel and SPSS version 14. The following data items were available from the admissions and discharge books - name, age, sex, reason for admission to NICU, labour ward weight, admission weight, date of birth, time of birth, date of admission, time of admission, labour ward, mother's ward, gestation at birth, mode of delivery, mother's parity, mother's age, discharge weight, date of discharge or death, time of discharge or death.

\section{RESULTS}

\section{Number of admissions}

Over the 5-year period, 9213 babies were admitted, a mean of 1843 per annum. Admissions peaked in 20132014 then dropped in 2015 - see Figure 1. The numbers of deliveries in KBTH were 2011 - 10503, 2012 - 10278, 2013 - 11186, $2014-10732$, and 2015 - 9215; a total of 51,914 deliveries with mean of 10,383 per annum. There were 7035 inborn admissions, representing an admission rate of $13.6 \%$ for babies delivered in $\mathrm{KBTH}$.

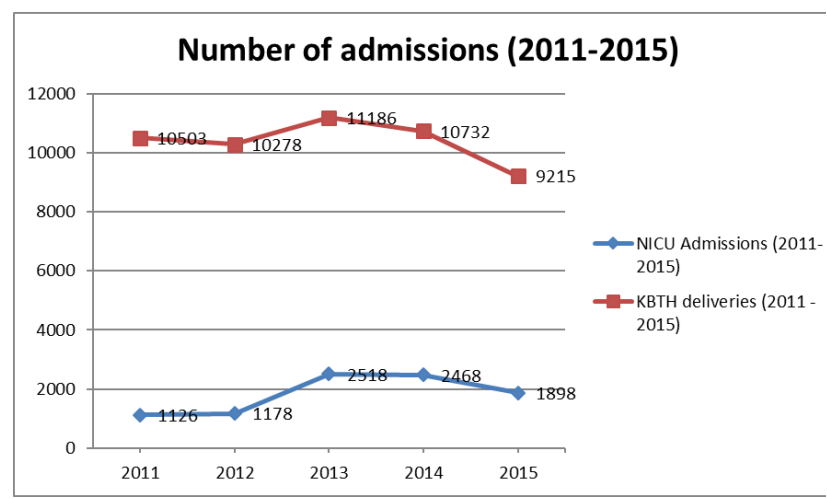

Figure 1 Number of deliveries in KBTH and NICU admissions from 2011 to 2015

Table 1 Admissions and mortality by sex

\begin{tabular}{|c|c|c|c|}
\hline Sex & $\begin{array}{l}\text { Number of ad- } \\
\text { missions }(\% \text { of } \\
\text { total admissions }) \\
{[95 \% \mathrm{CI}]}\end{array}$ & $\begin{array}{l}\text { Number of } \\
\text { deaths (\% of } \\
\text { total deaths) } \\
{[95 \% \mathrm{CI}]}\end{array}$ & $\begin{array}{l}\text { Sex-specific } \\
\text { Percentage } \\
\text { mortality } \\
(95 \% \text { CI })\end{array}$ \\
\hline Male & $\begin{array}{l}4998(54.2) \\
{[53.2-55.3]}\end{array}$ & $\begin{array}{l}963(54.5) \\
{[52.2-56.8]}\end{array}$ & $\begin{array}{l}19.3 \\
(18.2-20.4)\end{array}$ \\
\hline Female & $\begin{array}{l}4148(45.0) \\
{[44.0-46.0]}\end{array}$ & $\begin{array}{l}793(44.9) \\
{[42.5-47.1]}\end{array}$ & $\begin{array}{l}19.1 \\
(17.9-20.3)\end{array}$ \\
\hline $\begin{array}{l}\text { Indetermi- } \\
\text { nate (Ambig- } \\
\text { uous) }\end{array}$ & $5(0.05)[0.0-0.1]$ & $\begin{array}{l}3(0.2) \quad[0.0- \\
0.4]\end{array}$ & $\begin{array}{l}60.0 \\
102.9)\end{array}$ \\
\hline Missing data & 62 & $\begin{array}{l}8(0.5) \\
{[0.1-0.8]}\end{array}$ & $\begin{array}{l}12.9 \\
(4.6-21.2)\end{array}$ \\
\hline Total & 9213 & 1767 & \\
\hline
\end{tabular}

Below admission weight of $2500 \mathrm{~g}$, over the 5 -year period, there were 4531 admissions with annual mean of 906 , representing $49.2 \%$ of the total. For admissions below $1500 \mathrm{~g}$, there were 1727 , with annual mean of 365 , representing $18.8 \%$ of the total. Below $500 \mathrm{~g}$, there were 42 admissions with an annual mean of 8 and representing $0.5 \%$ of the total. More males than females were admitted; there was no significant difference in their mortality rates. (p-value: 0.81 )

\section{Admissions by Gestational Age}

Over the five-year period, preterm babies accounted for $48 \%$ of admissions, term admissions $45 \%$, post-term babies $4 \%$ and missing gestation $3 \%$. There were 3383 preterm babies delivered in KBTH during the period, representing $6.5 \%$ of total deliveries, compared to 26,375 term babies, representing $50.8 \%$. The breakdown of admissions by gestational age for the individual years is shown in Figure 2.

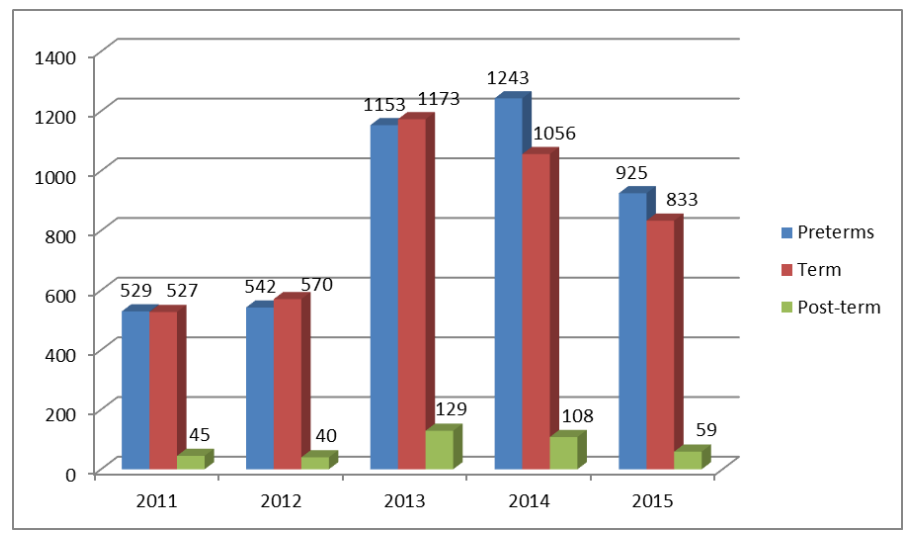

Figure 2 Number of admissions by gestation from 20112015

\section{Admission weights}

Admission weights ranged from $300 \mathrm{~g}$ to $6700 \mathrm{~g}$ with median of $2400 \mathrm{~g}$. The baby who weighed $6700 \mathrm{~g}$ had massive hydrocephalus. Babies with admission weight below $600 \mathrm{~g}$ represented $1 \%$ of all admissions.

\section{Age of neonates when admitted}

Majority (91\%) of the neonates were admitted on the day of delivery, and a further $6 \%$ by the end of the next day. Further details are shown in Table 2.

\section{Mortalities}

Table 3 shows that out of 9,213 neonates admitted over the five-year period, 1,767 died before discharge, an overall mortality rate of $19.2 \%$. There were statistically significant differences in mortality rate among neonates born $<26$ weeks, $26-27$ weeks, $28-31$ weeks and $>32$ weeks; the earlier the gestation the higher the mortality rate. Neonates less than 26 weeks gestation had the 
highest gestation-specific mortality rate of $80.2 \%$. Beyond 32 weeks gestation, mortality rates were not significantly different as shown in Figure 3.

Table 2 Age of neonates when admitted

\begin{tabular}{|c|c|}
\hline Age in days & $\begin{array}{l}\text { Number of ba- } \\
\text { bies (\%) }\end{array}$ \\
\hline 0 (day of delivery) & $8366(90.8)$ \\
\hline 1 & $557(6.0)$ \\
\hline 2 & $137(1.5)$ \\
\hline 3 & $36 \quad(0.4)$ \\
\hline 4 & $21 \quad(0.2)$ \\
\hline 5 & $7 \quad(0.1)$ \\
\hline 6 & $(0.0)$ \\
\hline 7 & $(0.1)$ \\
\hline $8-14$ & $4 \quad(0.0)$ \\
\hline Not stated & $75 \quad(0.8)$ \\
\hline Total & $9213(100)$ \\
\hline
\end{tabular}

Table 3 Admissions and mortalities by gestation

\begin{tabular}{|c|c|c|c|c|}
\hline Group & Weeks & $\begin{array}{l}\text { Number } \\
\text { admit- } \\
\text { ted }\end{array}$ & $\begin{array}{l}\text { Num- } \\
\text { ber of } \\
\text { deaths }\end{array}$ & \begin{tabular}{lr}
\multicolumn{3}{l}{ Gestational age- } \\
specific & mortal- \\
ity/100 with \\
$\mathbf{9 5 \%}$ CI
\end{tabular} \\
\hline \multirow{2}{*}{$\begin{array}{l}\text { Extreme pre- } \\
\text { term }\end{array}$} & $<26$ & 237 & 190 & $80.2[75.1-85.2]$ \\
\hline & $26-27$ & 302 & 208 & $68.9[63.7-74.1]$ \\
\hline Very preterm & $28-31$ & 1326 & 441 & $33.2[30.6-35.7]$ \\
\hline $\begin{array}{l}\text { Moderate pre- } \\
\text { term }\end{array}$ & $32-33$ & 1027 & 138 & 13.4 [11.4-15.6] \\
\hline Late preterm & $34-36$ & 1500 & 158 & $10.5[9.0-12.1]$ \\
\hline Early term & $37-38$ & 1359 & 181 & $13.3[11.5-15.1]$ \\
\hline Full term & $39-40$ & 1535 & 191 & $12.6[10.9-14.2]$ \\
\hline Late term & $41-42$ & 873 & 101 & 11.6 [9.4-13.7] \\
\hline Post term & $>42$ & 371 & 50 & $13.5[10.0-17.0]$ \\
\hline Incomplete data & Not stated & 939 & & \\
\hline Total & & 9213 & 1767 & $19.2[18.4-20.0]$ \\
\hline
\end{tabular}

Table 4 shows that neonates born before 37 weeks had about twice the mortality rate of those born after 37 weeks, with no significant difference between term and post-term gestations.

\section{Number of admissions and deaths by admission weight}

Table 5 and Figure 4 show that mortality rate was generally lower for babies with higher admission weights. There were significant differences among babies with admission weights $<750 \mathrm{~g}, 750-999 \mathrm{~g}, 1000-1499 \mathrm{~g}$ and $1500-2499 \mathrm{~g}$. There was no difference in mortality rate between the $1500-2499 \mathrm{~g}$ and over-2500g groups. $10 \%$ of babies with admission weight less than $750 \mathrm{~g}$ survived to discharge.

Table 4 Admissions and mortalities classified by preterm, term and post-term.

\begin{tabular}{|c|c|c|c|}
\hline Gestation & $\begin{array}{l}\text { Number } \\
\text { admitted }\end{array}$ & $\begin{array}{l}\text { Number } \\
\text { of mortali- } \\
\text { ties }\end{array}$ & $\begin{array}{l}\text { Gestation-specific } \\
\text { mortality } / 100 \quad(95 \% \\
\text { C.I. })\end{array}$ \\
\hline Preterm & 4399 & 1137 & $25.8[24.5-27.1]$ \\
\hline Term & 4165 & 508 & $12.2[11.2-13.2]$ \\
\hline Post-term & 371 & 50 & $13.5[10.0-17.0]$ \\
\hline $\begin{array}{l}\text { Incomplete } \\
\text { data }\end{array}$ & 278 & 72 & \\
\hline Total & 9213 & 1767 & $19.2[18.4-20.0]$ \\
\hline
\end{tabular}

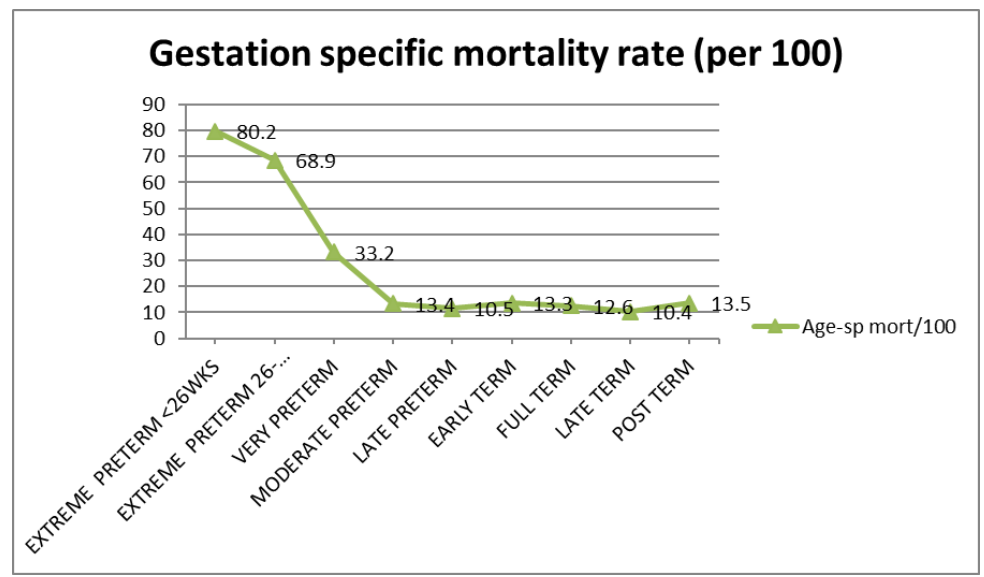

Figure 3 Gestation specific mortality rate (per 100)

Table 5 Number of admissions and deaths by admission weight

\begin{tabular}{|c|c|c|c|c|c|}
\hline $\begin{array}{l}\text { Admission } \\
\text { weight }\end{array}$ & $\begin{array}{l}\text { Number }(\%) \text { of } \\
\text { admissions }\end{array}$ & $\begin{array}{l}\text { Number }(\%) \\
\text { of deaths }\end{array}$ & $\begin{array}{l}\text { Admission weight-specific } \\
\text { mortality rate }(\%)(95 \% \text { CI })\end{array}$ & $\begin{array}{l}\text { Odds ratio }(95 \% \\
\text { C.I })\end{array}$ & p-value \\
\hline$<750 \mathrm{~g}$ & $237 \quad 2.6 \%$ & $213(12.0 \%)$ & $90.0(86.0-93.7)$ & $0.01(0.01-0.02)^{\prime}$ & $<0.0001$ \\
\hline $750-999 \mathrm{~g}$ & $323 \quad 3.5 \%$ & $234(13.2 \%)$ & $72.4(67.6-77.3)$ & $0.05(0.04-0.06)$ & $<0.0001$ \\
\hline $1000-1499 \mathrm{~g}$ & $1167 \quad 12.7 \%$ & $403(22.8 \%)$ & $34.5(31.8-37.3)$ & $0.25(0.21-0.29)$ & $<0.0001$ \\
\hline $1500-2499 \mathrm{~g}$ & $280430.4 \%$ & $318(18.0 \%)$ & $11.3(10.2-12.5)$ & $1.02(0.88-1.18)$ & 0.8342 \\
\hline $\begin{array}{l}2500 g \quad \text { and } \\
\text { above }\end{array}$ & $446948.5 \%$ & $514(29.1 \%)$ & $11.5(10.6-12.5)$ & Ref & \\
\hline Missing data & $213 \quad 2.3 \%$ & $85 \quad(4.8 \%)$ & $40.0(33.3-46.5)$ & & \\
\hline Total & $9213100 \%$ & $1767(100 \%)$ & & & \\
\hline
\end{tabular}




\section{Original Article}

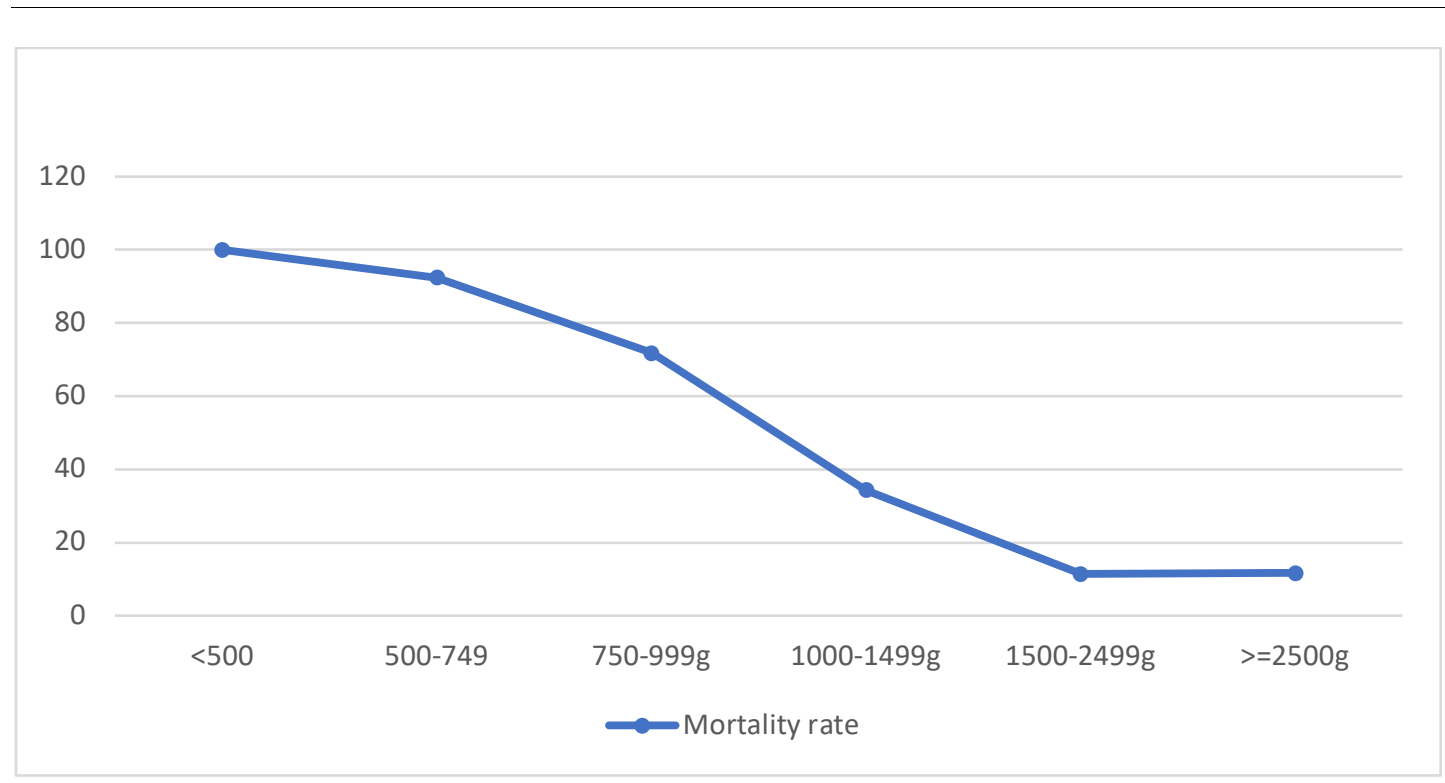

Figure 4 Mortality rate by admission weight

Table 6 Admissions and deaths for admission weights $<750 \mathrm{~g}$

\begin{tabular}{|c|c|c|c|c|c|}
\hline $\begin{array}{l}\text { Admission } \\
\text { weight (g) }\end{array}$ & $\begin{array}{l}\text { Number }(\%) \text { of } \\
\text { admissions }\end{array}$ & Number of deaths & $\begin{array}{l}\text { Admission weight }- \text { specific } \\
\text { mortality rate }(\%)(95 \% \\
\text { CI) }\end{array}$ & $\begin{array}{l}\text { Odds ratio } \quad(95 \% \\
\text { C.I) }\end{array}$ & p-value \\
\hline 300-349 & 6 & 6 & $100(100-100)$ & $0.02(0.00-0.28)$ & 0.0045 \\
\hline 350-399 & 6 & 6 & 100 & $0.02(0.00-0.28)$ & 0.0045 \\
\hline 400-449 & 27 & 27 & 100 & $0.02(0.00-0.28)$ & 0.0045 \\
\hline $450-499$ & 3 & 3 & 100 & $0.02(0.00-0.28)$ & 0.0045 \\
\hline $500-549$ & 55 & $51 / 53(* 2$ missing data) & $96.2(91.1-100)$ & $0.01(0.00-0.03)$ & $<0.0001$ \\
\hline $550-599$ & 7 & 6 & $85.7(60.0-100)$ & $0.03(0.00-0.28)$ & 0.0017 \\
\hline $600-649$ & 41 & $36 / 38(* 3$ missing data $)$ & $94.7(87.6-100)$ & $0.01(0.00-0.05)$ & $<0.0001$ \\
\hline $650-699$ & 15 & 13 & $86.7(69.5-100)$ & $0.03(0.01-0.14)$ & $<0.0001$ \\
\hline 700-749 & 77 & $65 / 72(* 5$ missing data $)$ & $90.3(83.4-97.1)$ & $0.02(0.01-0.05)$ & $<0.0001$ \\
\hline Sub-Total & $\begin{array}{l}237 \\
(10 \text { with missing } \\
\text { outcome data) }\end{array}$ & 213 & & & \\
\hline$\geq 750$ & 8763 & 1469 & $16.8(16.0-17.5)$ & Ref & \\
\hline Missing data & 213 & 85 & & & \\
\hline Total & 9213 & 1767 & 19.2 & & \\
\hline
\end{tabular}

Table 6 shows that there were no survivors among the 42 babies with admission weights less than 500g. Of 195 babies with admission weights between 500 and $749 \mathrm{~g}$, the estimated mortality rate was between $73 \%$ and $92 \%$ (as the outcome for 9 babies is unknown). The mortality rate for the VLBW group (500 - 1499g) was 53\%

$(1018 / 1912)$. There was a statistically significant difference $(95 \%$ C.I.) in mortality rate between the $700-749 \mathrm{~g}$ admission weight group and those $<500 \mathrm{~g}$. The mortality rate for the $>749 \mathrm{~g}$ group was significantly lower than the $<750 \mathrm{~g}$ group, with odds ratios and $\mathrm{p}$-values as shown in Table 6.

Table 7 Mortality by place of delivery

\begin{tabular}{|l|l|l|l|l|}
$\begin{array}{l}\text { Place of delivery } \\
\text { Number of admissions }\end{array}$ & $\begin{array}{l}\text { Number of deaths (\%) of } \\
\text { total deaths) [95\% C.I] }\end{array}$ & $\begin{array}{l}\text { Place-specific Percent- } \\
\text { age mortality [95\% C.I] }\end{array}$ & p-value \\
\hline Inborn & $7035(76.4 \%)$ & $1112(63 \%)[61-65]$ & $15.8[15.0-16.7]$ & $<0.05$ \\
\hline Outborn & $2112(22.9 \%)$ & $638(36 \%)[34-38]$ & $30.2[28.3-32.2]$ & \\
\hline No entry & $66(0.7 \%)$ & $17(1 \%)$ & & \\
\hline Total & 9213 & 1767 & & \\
\hline
\end{tabular}

Compared to babies born in KBTH, those born outside KBTH were significantly more likely to die, $15.8 \%$ and $30 \%$ mortality rates respectively (Table 7). 
Table 8 Admissions and Mortalities by day of week

\begin{tabular}{|l|l|l|l|l|}
\hline Day of week & $\begin{array}{l}\text { Number of } \\
\text { admissions }\end{array}$ & $\begin{array}{l}\text { Percentage of all admis- } \\
\text { sions (95\% CI) }\end{array}$ & $\begin{array}{l}\text { Number of } \\
\text { deaths }\end{array}$ & $\begin{array}{l}\text { Percentage } \\
\text { deaths (95\% CI) }\end{array}$ \\
\hline Sunday & 1165 & $12.6(11.9-13.3)$ & 281 & $15.9(14.2-17.6)$ \\
\hline Monday & 1195 & $13.0(12.3-13.7)$ & 227 & $12.8(11.3-14.4)$ \\
\hline Tuesday & 1419 & $15.4(14.7-16.1)$ & 260 & $14.7(13.0-16.3)$ \\
\hline Wednesday & 1394 & $15.1(14.4-15.8)$ & 264 & $15.0(13.3-16.6)$ \\
\hline Thursday & 1304 & $14.2(13.5-14.9)$ & 250 & $14.1(12.5-15.8)$ \\
\hline Friday & 1355 & $14.7(14.0-15.4)$ & 234 & $13.2(11.6-14.8)$ \\
\hline Saturday & 1338 & $14.5(13.8-15.2)$ & 242 & $13.7(12.1-15.3)$ \\
\hline Missing data & 43 & 0.5 & 9 & $100 \%$ \\
\hline Total & 9213 & $100 \%$ & 1767 & \\
\hline
\end{tabular}

There was a significantly low number of admissions on Sundays and Mondays (95\% C.I. as shown in Table 8). The highest number of deaths (281) and percentage mortality $(15.9 \%)$ of the week was recorded on Sundays. The lowest number of deaths (227) and percentage mortality $(12.8 \%)$ was on Mondays, and was significantly lower than on Sundays $(\mathrm{p}=0.0086)$

\section{How long after admission do babies die?}

Forty-nine percent of those who died did so within 48 hours of admission; and $66 \%$ within 72 hours. By the end of the seventh day, $83 \%$ of the deaths had occurred. Of the 869 babies who died within 48 hours, 59.6\% were preterm, $31.9 \%$ were term, $4.1 \%$ were post-term and $4.4 \%$ were of unspecified gestation (Table 9 ).
Table 9 Duration of survival of babies who die on admission

\begin{tabular}{|l|l|l}
$\begin{array}{l}\text { Time from } \\
\text { admission to } \\
\text { death }\end{array}$ & $\begin{array}{l}\text { Number } \\
\text { of deaths }\end{array}$ & $\begin{array}{l}\text { Percentage mortal- } \\
\text { ity (95\% CI) }\end{array}$ \\
\hline Within 24hrs & 432 & $24.4(22.4-26.4)$ \\
\hline $\mathbf{2 4 - < 4 8 h r s ~}$ & 437 & $24.7(22.7-26.7)$ \\
\hline $\mathbf{4 8}-<\mathbf{7 2 h r s}$ & 298 & $16.9(15.1-18.6)$ \\
\hline 3 days & 125 & $7.1(5.9-8.3)$ \\
\hline 4 days & 71 & $4.0(3.1-4.9)$ \\
\hline 5 days & 55 & $3.1(2.3-3.9)$ \\
\hline 6 days & 47 & $2.7(1.9-3.4)$ \\
\hline 7 days & 36 & $2.0(1.4-2.7)$ \\
\hline 8 days & 35 & $2.0(1.3-2.6)$ \\
\hline 9 days & 24 & $1.4(0.8-1.9)$ \\
\hline 10 days & 21 & $1.2(0.6-1.7)$ \\
\hline 11 days & 19 & $1.1(0.6-1.6)$ \\
\hline 12 days & 13 & $0.7(0.3-1.1)$ \\
\hline 13days & 8 & $0.5(0.1-0.8)$ \\
\hline 14days & 3 & $0.2(0.0-0.4)$ \\
\hline 15 days & 12 & $0.7(0.3-1.1)$ \\
\hline >15 days & 101 & $5.7(4.6-6.8)$ \\
\hline Missing data & 30 & 1.7 \\
\hline Total & 1767 & 100 \\
\hline & &
\end{tabular}

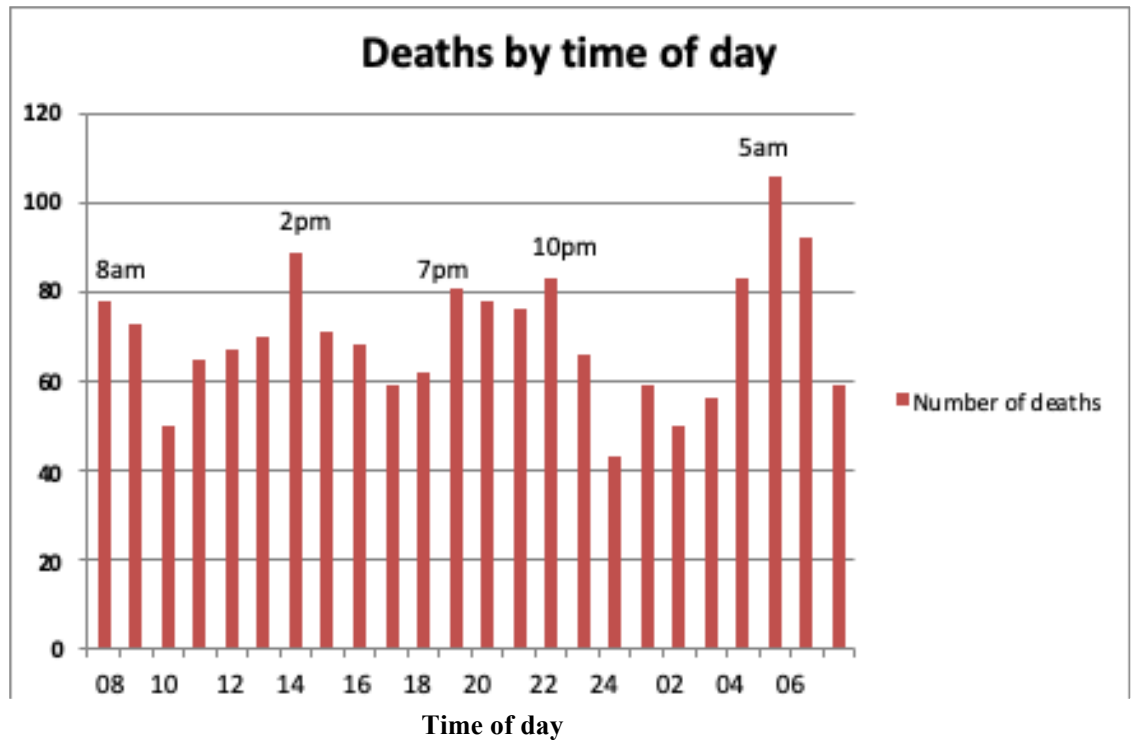

Figure 5 Number of deaths by time of day 
Due to inadequate monitoring for apnoea, the recorded time of death may have been later than the actual event. There were significantly more deaths during the night shift than during the day shifts $(\mathrm{p}<0.05)$, with a peak period from 5 am to $6 \mathrm{am}$, and trough at midnight.

\section{Missing data}

Some data were missing due to incomplete entries and torn pages in the A \& D book. The percentages of missing data ranged from $0.2-6.0 \%$ with median of $1.4 \%$ (Table $10)$.

Table 10 Number of missing entries by category

\begin{tabular}{|l|l|l|}
\hline Category & $\begin{array}{l}\text { Number of en- } \\
\text { tries missing }\end{array}$ & $\begin{array}{l}\text { Percentage of to- } \\
\text { tal entries (9213) }\end{array}$ \\
\hline Year of delivery & 22 & 0.2 \\
\hline Gestational age & 268 & 2.9 \\
\hline Maternal age & 557 & 6.0 \\
\hline Admission weight & 213 & 2.3 \\
\hline Age at admission & 75 & 0.8 \\
\hline Mode of delivery & 55 & 0.6 \\
\hline Outcomes & 512 & 5.6 \\
\hline Admissions by day of week & 43 & 0.5 \\
\hline Deaths by birth weight & 179 & 1.9 \\
\hline Source of referral & 66 & 0.7 \\
\hline
\end{tabular}

\section{Limitations}

Gestations recorded in the A\&D books were determined by dates (last menstrual period or early antenatal ultrasound) and therefore subject to the errors inherent in that. Babies admitted to the NICU with suspected self-limiting diagnoses and who were discharged before 24 hours were not entered into the A\&D book. The numbers reported here are therefore an underestimate of the unit's workload.

The NICU admits all babies born in KBTH who need immediate medical care. These are babies who are preterm, low birth weight, clinically ill, dysmorphic or those considered to be at significant risk of infection, jaundice or hypoglycaemia. The unit also admits out-born babies who have not yet been home, have not received any vaccines and are less than 24 hours old. KBTH NICU generally does not admit babies, whether inborn or out-born, who do not fit these criteria. Such babies are admitted to a separate Babies Unit in the children's department.

Admission weights have been quoted rather than birth weight because there were significant differences between weights recorded in the labour ward and in the NICU, even when babies were admitted within minutes of birth. $96.8 \%$ of babies were admitted within a day of birth, so the admission weight in these cases would not be significantly different from weight immediately after birth.
Since our data are from only one tertiary institution, they probably do not reflect what pertains in the rest of the country. For example, it is not known what proportion of preterm infants receives any medical care in the rest of the country.

\section{DISCUSSION}

The number of admissions to the NICU was directly related to the number of deliveries conducted in the Obstetrics Department of the Korle-Bu Teaching Hospital, which was the source of the majority $(76 \%)$ of NICU admissions.

\section{Mortality by sex}

We found no significant difference in mortality rates between males and females, similar to reports by Jehan from urban Pakistan. ${ }^{1}$ In contrast, using a large database in the United States, Zhao found that the odds of neonatal mortality and other perinatal outcomes were higher among male twins than their female co-twins in mixedsex pairs. There was however no sex difference in foetal mortality. $^{2}$

The overall mortality rate in our study was $19.2 \%$; Jehan reported a mean neonatal mortality rate of $47.3 \%$ whilst Zhao reported a neonatal mortality rate of about $2 \%$. Though the study methodologies and populations are different, these figures suggest that perhaps when mortality rates are very high, sex differences may be obscured.

The finding that preterm babies represented almost half (48\%) of all admissions is partly accounted for by hospital policy which directs that all preterm babies delivered in KBTH should be admitted to NICU. The vast majority of babies were admitted within a day of birth. This is due to the hospital policy of admitting all preterms and also not admitting to the NICU, babies who become ill after discharge. A further possible explanation is that most causes of admission are present at birth.

\section{Comparison of worldwide mortality rates}

Comparison of mortality rates among different facilities and over different periods of time is fraught with problems including reliability of data, and different ranges of parameters such as gestation and birth weight. It has been suggested that birth weights less than $500 \mathrm{~g}$ be excluded from analysis to achieve some level of uniformity across publications. ${ }^{3,4} \mathrm{~A}$ further difficulty in comparisons is uncertainty about how ill the admitted infants were. Not surprisingly, reported mortality rates for admissions involving all gestations vary widely from $3.1 \%$ to $29 \%{ }^{5}$ From South Africa, Pepler reported a mortality rate of $3.1 \%$ in neonates from 23 to 42 weeks gestation, born in 2007-2008 and managed in private NICUs. ${ }^{6}$ 


\section{Original Article}

Shakaran reported a mortality rate of $4 \%$ in neonates of all gestations born in Canada in 1996-1997. ${ }^{7}$ From Australia, Feng reported $8.3 \%$ for $2001-2006 .{ }^{8}$ In England, Mankelow reported $8.1 \%$ for 2008 - 2010. ${ }^{9}$ Costa reported 5.7\% from Portugal in $2004-2008 .{ }^{10}$ For neonates with "severe perinatal morbidity" above 28 weeks gestation, Musooka in Uganda, reported a mortality rate of $26-29 \%$ in $2013 .{ }^{11}$

In 2009, Shim reported data for 2,584 very low birth weight infants admitted to NICUs in 76 hospitals in S Korea. ${ }^{12}$ For babies with birth weight less than $750 \mathrm{~g}$, mortality rate was $45 \% ; 750-999 \mathrm{~g} 20 \% ; 1000 \mathrm{~g}-1499 \mathrm{~g}$ $6.5 \%$ compared to $89 \%, 72 \%$ and $34 \%$ respectively in our NICU. For the $500 \mathrm{~g}-1499$ group, our estimated mortality rate was 53\%; in S Korea the rates were $15 \%$ for 2007 , $33 \%$ in 1996 , and $68 \%$ in the early $1960 \mathrm{~s}^{12}$

Atiah in a study at the NICU of another hospital in Accra reported a mortality rate of $85.5 \%$ for babies with birth weights below $1.5 \mathrm{~kg} .{ }^{13}$ The equivalent rate for our unit was $49 \%$. From North Western Ethiopia, Woldehanna et al, in a study involving 304 neonates admitted to a paediatric ward from 1994 to 1999, reported an overall mortality rate of $41 \%$; in the VLBW group, the mortality rate was $80 \%{ }^{14}$

In a study of 135 babies with birth weights $600 \mathrm{~g}$ to $2500 \mathrm{~g}$ and gestation 26 to 38 weeks at the NICU of Kenyatta National Hospital, an overall mortality rate of $46 \%$ was reported. ${ }^{15}$ In Cairo, of 113 babies with birth weight between 700 and $1500 \mathrm{~g}$, mortality rate was $35 \% .{ }^{16}$ In our study, 699 out of the 1566 babies born between 700 and $1500 \mathrm{~g}$ died, giving a mortality rate of $44.6 \%$

\section{Why higher mortality rates?}

These differences in outcome are attributable to various factors including the severity of illness of patients, the absolute level of resources devoted to obstetric and neonatal care, as well as efficient organisation of national and local resources. ${ }^{11,16,17}$ Within countries, facilities that offer higher-level neonatal intensive care services and treat larger numbers of patients are reported to have better mortality outcomes. ${ }^{4}$

As far as it is possible to compare, the KBTH NICU has similar mortality rates to other low-resource NICUs, presumably because the challenges and constraints are the same. Compared to higher income countries, there are many possible reasons why the KBTH NICU mortality rates are higher. The KBTH NICU currently does not provide mechanical ventilation though it admits VLBW and other seriously ill infants; an anomaly that reflects the mismatch, in low resource areas, between what is needed and what can be provided. The KBTH NICU therefore fits into neither level 2 nor $3 \mathrm{~A}$ of the draft version of the American Academy of Pediatrics report on NICU levels of care. ${ }^{3}$ A suggested level for such units could be "level 2 plus".

To compound the problem of illness severity is the issue of volume. Ciaran et al defined a high-volume unit as one that treats more than $100 \mathrm{VLBW}$ infants annually. ${ }^{4}$ The KBTH NICU would therefore be rated as a very highvolume unit as it admits a mean of 365 VLBW infants annually. Closely linked to the high volumes is the problem of insufficient staff, in particular, general and neonatal nurses, administrative and clerical staff, and medical engineers. A further issue is the inability of many families to afford basic neonatal care, let alone intensive care. $^{18}$

The problem of determining whether differences in mortality between NICUs are primarily due to differences in illness severity or quality of care may be addressed in future studies by the use of Illness severity scores such as the Clinical Risk Index for Babies (CRIB II). ${ }^{19}$ 20,21 22

Our data are comparable to those from other LMICs but much worse than outcomes in higher income countries. Recent studies from Pakistan and other low-resource settings indicate that substandard care, inadequate training, low staff competence and a lack of resources, including equipment and medication, are all factors that contribute to neonatal deaths. ${ }^{1}$ These deficits are likely due to poorer organisation of the countries in general, resulting in lower productivity and GDP, compounded by misallocation of resources.

To substantially improve perinatal and neonatal outcomes, there is the need for both wider health-care coverage and better quality of health care including clinical audits. ${ }^{1}$ Neogi reported from India that high patient volume ( $>2,000$ deliveries/year), inborn status, availability of referral system and inter-facility transfers, and adequate nursing care staff in neonatal units also demonstrated protective effect in averting neonatal deaths. ${ }^{23}$ This confirms that complex interventions are necessary to improve outcomes, not just an increase in the allocation of particular resources. ${ }^{24}$

\section{How long after admission do babies die?}

The fact that $66 \%$ of deaths occurred within 72 hours of admission is probably a reflection of the severity of illnesses babies come in with, and perhaps the lack of highlevel intensive care facilities such as intermittent positive pressure ventilation. These findings are similar to reports from Bhopal, India where $75 \%$ of deaths occurred in the first week; and from Ogun State, Nigeria where 39\% of deaths occurred in the first 24 hours. ${ }^{26,27}$ 


\section{Times of day when deaths occur.}

The higher nocturnal mortality rate coincides with, and may be causally related to, the lower number of nurses and doctors at night ${ }^{28}$. Typically, the ratio of all grades of nurses providing bedside care ranges from 10:1 for the $8 \mathrm{am}$ to $2 \mathrm{pm}$ shift, to $18: 1$ for the $8 \mathrm{pm}$ to $8 \mathrm{am}$ shift. Other potential contributory factors may include reduced ambient lighting, reduced alertness of staff and lack of parental presence. ${ }^{29}$

Mortality rate was significantly higher among outborn babies. The possible reasons include suboptimal antenatal and perinatal care e.g. antenatal steroids, and poor transport conditions resulting in more severe illness. In a study involving 894 infants born at 23 to 32 weeks' gestation, outborn babies were found to have a higher frequency of severe intraventricular haemorrhage associated with lower uptake of antenatal steroids. ${ }^{30}$ It has been postulated that when considering referral to higher level facilities, the babies referred are those considered by the referrer to be most likely to survive.

Therefore, babies with worse prognosis, and considered less likely to benefit from referral, are not referred. ${ }^{3}$ If this selection bias occurs in our area, it suggests that there may be an even larger difference in outcomes between higher level and lower level facilities. The significantly low number of admissions on Sundays and Mondays is not accounted for by transfers from other hospitals and may therefore be due to fewer local births on those days.

In the absence of increased resources there may be a need to ration care - in order to optimise outcomes for those with better prognosis. There were 195 infants (2.1\% of all admissions) with admission weight between 500 and $749 \mathrm{~g}$; and 42 infants ( $0.5 \%$ of admissions) below $500 \mathrm{~g}$. Based on current survival rates, an option may be to offer only comfort care to neonates with birth weights below $500 \mathrm{~g} .{ }^{31,} 32$ For neonates with admission weights between $500 \mathrm{~g}$ and $750 \mathrm{~g}$, whose overall mortality rate is $90 \%$, a possible approach could be to offer resuscitation at birth if they are vigorous and without severe congenital malformations; but if subsequently they require resuscitation, to consider limiting its intensity and duration. However, considering the basic level of care currently provided, efforts should also be directed towards improving the range and quality of services in the unit.

\section{Missing data}

Although there is no established threshold for determining what percentage of missing data is acceptable, between 5 and $10 \%$ has been quoted in the literature. ${ }^{25}$ Using this criterion, the missing data percentage of between 0.5 and $6.0 \%$ in this study, falls within acceptable limits.

\section{CONCLUSION}

We report a relatively high NICU mortality rate of $19.2 \%$, compared to the worldwide range of $3.1 \%$ to $29 \%$. This wide range of outcomes may be attributed to differences in the severity of illness of patients and to the organisation of resources devoted to obstetric and neonatal care. To substantially improve perinatal and neonatal outcomes, there is a need for wider coverage and better quality of health care; and to consider rationing of care. Complex interventions are necessary to improve outcomes, not just an increase in the allocation of particular resources.

\section{ACKNOWLEDGEMENT}

Mrs Jemima Palm, KBTH NICU matron, for providing the Admission and Discharge books. Dr Eric Odei of KBTH helped with statistical analysis.

\section{REFERENCES}

1. Jehan I, Harris H, Salat S, et al. Neonatal mortality: risk factors and causes: a prospective population based cohort study in Pakistan. Bull World Health Organ. 2009;87(2):130-8.

2. Zhao D, Zou L, Lei X, et al. Gender Differences in Infant Mortality and Neonatal Morbidity in Mixed-Gender Twins. Scientific Reports. 2017;7: 8736

3. Barfield WD, Levels of Neonatal Care, Policy Statement From the American Academy of Pediatrics. Pediatrics. 2012;130(3)

4. Phibbs CS, Baker LC, Caughey AC, et al. Level and Volume of Neonatal Intensive Care and Mortality in Very-Low-Birth-Weight Infants. N Engl J Med. 2007; 356:2165-2175

5. Chow S, Chow R, Popovic M, et al. A Selected Review of the Mortality Rates of Neonatal Intensive Care Units. Front Public Health. 2015; 3:225.

6. Pepler PT, Uys DW, Nel DG. Predicting mortality and length-of-stay for neonatal admissions to private hospital neonatal intensive care units: a South African retrospective study. Afr Health Sci. 2012;12(2):166-73.

7. Sankaran K, Chien LY, Walker R, et al. Variations in mortality rates among Canadian neonatal intensive care units. CMAJ. 2002;166(2):173-8.

8. Feng Y, Abdel-Latif ME, Bajuk B, et al. Causes of death in infants admitted to Australian neonatal intensive care units between 1995 and 2006. Acta Paediatr. 2013;102(1):e17-23.

9. Manktelow BN, Draper ES, Field D. Predicting neonatal mortality among very preterm infants: a comparison of three versions of the CRIB score. Arch Dis Child Fetal Neonatal E. 2010; 95(1): F9-F13.

10. Costa S, Rodrigues M, Centeno MJ, et al. Diagnosis and cause of death in a neonatal intensive care unit - 
How important is autopsy? $J$ Matern Fetal Neonatal Med. 2011;24(5):760-3.

11. Musooko M, Kakaire O, Nakimuli A, et al. Incidence and risk factors for early neonatal mortality in newborns with severe perinatal morbidity in Uganda. Int $J$ Gynaecol Obstet. 2014;127(2):201-5.

12. Shim JW, Kim MJ, Kim EK, et al. The impact of neonatal care resources on regional variation in neonatal mortality among very low birth weight infants in Korea. Paediatr Perinat Epidemiol. 2013;27(2):216-225

13. Atiah FA. Contribution of very low birth weight to preterm neonatal mortality at 37 Military Hospital, Accra. Dissertation submitted to the University of Ghana, Legon. 2016. [cited 2018 Jul 11]; [43 p]. http://197.255.68.203/handle/123456789/21389

14. Woldehanna TD, Idejene ET. Neonatal mortality in a teaching hospital, North Western Ethiopia. Cent Afr J Med. 2005;51(3-4):30-3

15. Marete IK, Wasunna AO, Otieno PA. Clinical risk index for babies (CRIB) II score as a predictor of neonatal mortality among low birth weight babies at Kenyatta National Hospital. East Afr Med $J$. 2011;88(1):18-23.

16. Ezz-Eldin ZM, Hamid TAA, Youssef MRL, et al. Clinical Risk Index for Babies (CRIB II) Scoring System in Prediction of Mortality in Premature Babies. $J$ Clin Diagn Res. 2015;9(6): SC08-SC11

17. Ensor T, Cooper S, Davidson L, et al. The impact of economic recession on maternal and infant mortality: lessons from history. BMC Public Health. 2010; 10:727.

18. Basnet S, Adhikari N, Koirala J. Challenges in setting up pediatric and neonatal intensive care units in a resource-limited country. Pediatrics. 2011;128(4): e986-92.

19. Jašić M, Dessardo NS, Rukavina KM. CRIB II score versus gestational age and birth weight in preterm infant mortality prediction: who will win the bet? SIGNA VITAE. 2016;11(1): 172-181

20. Ezz-Eldin ZM, Abdel Hamid TA, Youssef MRL, et al. Clinical Risk Index for Babies (CRIB II) Scoring System in Prediction of Mortality in Premature Babies. $J$ Clin Diagn Res. 2015;9(6): SC08-SC11

21. Rosenberg RE, Ahmed S, Saha SK, et al. Simplified age-weight mortality risk classification for very low birth weight infants in low-resource settings. $J$ Pediatr. 2008;153(4): 519-24.

22. Gooden M, Younger N, Trotman H. What is the Best Predictor of Mortality in a Very Low Birth Weight Infant Population with a High Mortality Rate in a Medical Setting with Limited Resources? Am J Perinatol 2014;31(6):441-6.

23. Neogi SB, Malhotra S, Zodpey S, et al. Does facility based newborn care improve neonatal outcomes? A review of evidence. Indian Pediatr. 2012;49(8):651-8.

24. Enweronu-Laryea CC, Nkyekyer KK, Rodrigues OP. The impact of improved neonatal intensive care facilities on referral pattern and outcome at a teaching hospital in Ghana. J Perinatol. 2008; 28:561-565

25. Dong Y, Peng C-YJ. Principled missing data methods for researchers. SpringerPlus. 2013; 2:222.

26. Verma J, Anand S, Kapoor N, Gedam S, Patel U. Neonatal outcome in newborns admitted in NICU of tertiary care hospital in central India: a 5-year study. Int J Contemp Pediatr 2018;5: 1364-7.

27. Ogunlesi T. Mortality within the First 24 Hours of Admission among Neonates aged Less than 24 Hours in a Special Care Baby Unit (SBCU) in Nigeria: The Role of Significant Hypothermia and Hypoglycemia. Iranian Journal of Neonatology 2015; 6(1) 1-7.

28. Pillay T, Nightingale P, Owen S, Kirby D Spencer A. Neonatal nurse staffing and delivery of clinical care in the SSBC Newborn Network. Arch Dis Child Fetal Neonatal Ed 2012; 97: F174-F178.

29. Bensouda B, Boucher J, Mandel R, et al. 24/7 in house attending staff coverage improves neonatal short-term outcomes: A retrospective study. Resuscitation. 2018;122: 25-28.

30. Palmer KG, Kronsberg SS, Barton BA, et al. Effect of inborn versus outborn delivery on clinical outcomes in ventilated preterm neonates: secondary results from the NEOPAIN trial. J Perinatol. 2005;25(4):270-275

31. Stringer M, Shaw VD, Savani RC. Comfort care of neonates at the end of life. Neonatal Netw. 2004;23(5):41-6.

32. Uthaya S, Mancini A, Beardsley C, et al. Managing palliation in the neonatal unit. Arch Dis Child Fetal Neonatal Ed. 2014 [cited 2018 Jul 11]; [4 p.]. doi:10.1136/ archdischild-2013-305845

Copyright (C) The Author(s). This is an Open Access article under the CC BY license. 